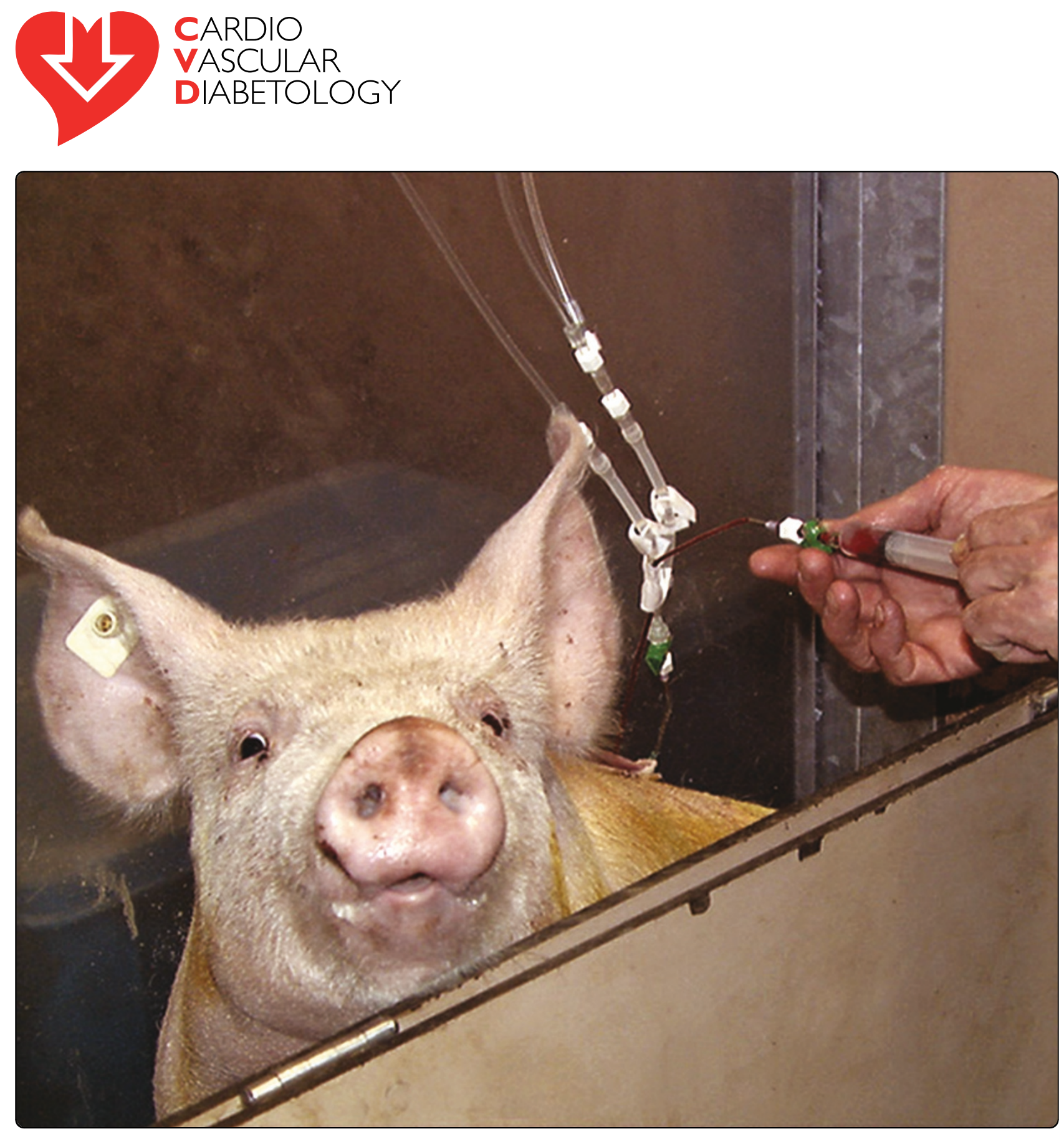

Dietary saturated fat/cholesterol, but not unsaturated fat or starch, induces C-reactive protein associated early atherosclerosis and ectopic fat deposition in diabetic pigs

Koopmans et al. 


\title{
Dietary saturated fat/cholesterol, but not unsaturated fat or starch, induces C-reactive protein associated early atherosclerosis and ectopic fat deposition in diabetic pigs
}

Sietse J Koopmans ${ }^{1,2^{*}}$, Ruud Dekker ${ }^{1}$, Mariette T Ackermans ${ }^{3}$, Hans P Sauerwein ${ }^{4}$, Mireille J Serlie ${ }^{4}$, Heleen MM van Beusekom ${ }^{5}$, Mieke van den Heuvel ${ }^{5}$ and Wim J van der Giessen

\begin{abstract}
Background: Diabetes is thought to accelerate cardiovascular disease depending on the type of diet. This study in diabetic subjects was performed to investigate the metabolic, inflammatory and cardiovascular effects of nutritional components typically present in a Western, Mediterranean or high glycaemic diet.

Methods: Streptozotocin-diabetic pigs ( $45 \mathrm{~kg}$ ) were fed for 10 weeks supplemental ( $40 \%$ of dietary energy) saturated fat/cholesterol (SFC), unsaturated fat (UF) or starch (S) in an eucaloric dietary intervention study.

Results: Fasting plasma total, LDL and HDL cholesterol concentrations were $3-5$ fold higher $(p<0.01)$ in SFC compared to UF and S pigs. Fasting plasma NEFA concentrations $(\mathrm{mmol} / \mathrm{L})$ were highest $(p<0.05)$ in SFC $(1.09 \pm$ $0.17)$, intermediate in UF $(0.80 \pm 0.14)$ and lowest in $S$ pigs $(0.58 \pm 0.14)$ whereas plasma glucose $(\sim 13 \mathrm{mmol} / \mathrm{L})$, triglyceride $(\sim 0.5 \mathrm{mmol} / \mathrm{L})$ and insulin $(\sim 24 \mathrm{pmol} / \mathrm{L})$ concentrations were comparable among SFC, UF and $S$ pigs. The postprandial response area under the curves (AUC, $0-4$ h) for glucose but not for insulin and triglyceride responses were intermediate in SFC $(617 \pm 144)$ and lowest $(p<0.05)$ in UF $(378 \pm 157)$ compared to S pigs (925 \pm 139). Fasting hepatic glucose production, hepatic and peripheral insulin sensitivity and blood pressure were not different among pigs. C-reactive protein (CRP) concentrations (mg/L) were highest $(p<0.05)$ in SFC $(25 \pm 4)$, intermediate in $S(21 \pm 3)$ and lowest in UF pigs (14 \pm 2$)$. Liver weights, liver and muscle triglyceride concentrations, and the surface area of aorta fatty streaks were highest $(p<0.01)$ in SFC pigs. A positive correlation between postprandial plasma CRP and aorta fatty streaks was observed in SFC pigs $\left(R^{2}=0.95\right)$. Retroperitoneal fat depot weight (g) was intermediate in SFC (260 \pm 72$)$, lowest in S (135 \pm 51$)$ and highest $(p<0.05)$ in UF $(571 \pm 95)$ pigs.
\end{abstract}

Conclusion: Dietary saturated fat/cholesterol induces inflammation, atherosclerosis and ectopic fat deposition whereas an equally high dietary unsaturated fat load does not induce these abnormalities and shows beneficial effects on postprandial glycaemia in diabetic pigs.

Keywords: Diabetes, Insulin, Diet, Unsaturated fat, Saturated fat, Cholesterol, Inflammation, C-reactive protein, Atherosclerosis, Pigs

\footnotetext{
* Correspondence: sietsejan.koopmans@wur.nl

'BioMedical Research of Wageningen University and Research Center,

Lelystad, The Netherlands

Full list of author information is available at the end of the article
} 


\section{Background}

The impact of an excess in dietary fats and carbohydrates on metabolic control, inflammation and cardiovascular disease has been studied and discussed in normal and (pre)diabetic subjects in both human [1-4] and animal studies [5-7]. In general, excessive dietary saturated fats and cholesterol increase the risk for the development of obesity, diabetes and cardiovascular diseases $[6,8-10]$ while dietary unsaturated fats are considered less harmful and do not impose an increased risk for the development of diabetes and cardiovascular diseases $[1,2,6]$. Dietary carbohydrates, in the form of starches, have a high glycaemic load and thereby worsen postprandial glucose, stimulate insulin secretion and de novo lipogenesis [11-14].

Most studies on the longer term (months) effects of dietary components have been carried out in normal or glucose intolerant individuals but limited information is available in diabetic subjects on metabolic control, inflammation, cardiovascular abnormalities and body composition $[2,12,13,15]$.

Longer term studies in diabetic humans are difficult to perform because adherence to the prescribed diets has proven to be extremely difficult [16] and because dietary effects on the pathophysiology of diabetes are usually small with respect to metabolic control, insulin sensitivity, inflammation and cardiovascular diseases $[17,18]$. In addition, longer term studies are usually necessary to disclose any dietary effects on the pathophysiology of diabetes because part of the dietary effects are caused by changes in body composition. This can partly be overcome by studying animal models which are representative for the human situation, are highly homogenous and are kept under strictly standardized experimental conditions.

We have developed a pig model for diabetes mellitus type 2 in humans which is characterized by insulin resistance, hyperglycaemia as well as elevated plasma triglyceride and NEFA concentrations. The diabetic pigs are non-ketotic, anabolic and do not require insulin therapy [19]. Pigs are like humans omnivores and as such, the functionality of the gastrointestinal tract is comparable between pigs and man and therefore the pig is an useful animal model for the study of dietary components $[20,21]$. This makes the pig particular useful when the effect of diets is studied on diabetes accelerated dyslipidaemia and atherosclerosis [22-24]. Furthermore, coronary arteries of diabetic pigs have been shown to express low grade inflammation [25], a condition also described in humans with type 2 diabetes mellitus [13,26,27].

The aim of this dietary intervention study was to characterize and compare the medium/long-term (10 weeks) pathogenic effects of eucaloric diets 1 ) both high in supplemental fat, but differing in fat composition as reflected by mainly saturated fats and cholesterol (SFC) versus mainly unsaturated fats (UF) and 2) differing in supplemental fat (SFC or UF) versus supplemental carbohydrate (starch, S), on pre- and postprandial hyperglycaemia, lipidaemia and insulinaemia, on insulin sensitivity, blood pressure, circulating pro-inflammatory markers, retroperitoneal fat weight and on muscle, liver and aorta lipid deposits in diabetic pigs.

\section{Methods}

The performed research is in compliance with the ARRIVE guidelines on animal research [28]. Experimental protocols describing the management, surgical procedures, and animal care were reviewed and approved by the ASG-Lelystad Animal Care and Use Committee (Lelystad, The Netherlands).

\section{Animals, housing, diets and surgery}

Domestic (Landrace $\times$ Yorkshire, D-line) pigs (barrows with an initial age and body weight of $\sim 11$ weeks and $\sim 30 \mathrm{~kg}$, respectively) were obtained (Bastiaanse, Espel, The Netherlands) and kept in specially designed metabolic pens $(1.15 \times 1.35 \mathrm{~m})$ and adapted to the light/dark cycle (lights on at 05:00 $\mathrm{h}$ and off at 19:00 h) and a feeding schedule. Pigs were weighed weekly and the meal size was adjusted to the individual pig's weight. The pigs were fed 2.5-fold maintenance requirements for gross energy (GE) as established in a normal pig. This corresponded with a feeding level of $1045 \mathrm{~kJ} \mathrm{GE} \mathrm{kg}^{-1} \mathrm{BW}^{0.75}$ (metabolic weight of the pigs) per day and is sufficient to ensure moderate growth in normal pigs [29].

The pigs were fed a commercial pig diet $5 \%$ crude fat, $16 \%$ crude protein, $41 \%$ starch and sugars, $20 \%$ non-starch polysaccharides, $6 \%$ ash and $12 \%$ water; Startbrok; Agrifirm, Meppel, The Netherlands) twice daily (at 06:00 and 16:00 h). Water was always available ad libitum. After 1 week, pigs were provided with a permanent blood vessel catheter in the jugular vein, as previously described by us $[29,30]$. One week after surgery, 21 pigs were treated with streptozotocin $(140 \mathrm{mg} / \mathrm{kg})$ as described previously [19]. Two weeks thereafter, 3 pigs showed fasting plasma glucose concentrations $<10 \mathrm{mmol} / \mathrm{L}$ and were excluded from the study. The remaining 18 pigs were balanced over the 3 diet groups, based on fasting hyperglycaemia. Composition of the saturated fat/cholesterol, unsaturated fat and starch enriched diets is shown in Table 1. The experimental meals were fed twice daily (at $1045 \mathrm{~kJ} \mathrm{GE} \mathrm{kg}^{-1} \mathrm{BW}^{0.75}$ per day) for a duration of 10 weeks. In practical terms this means that the pigs on the starch-enriched diet were fed 1.31-fold the amount (on weight basis, but equal in caloric content) compared to the pigs on the fat-enriched diets in order to match the energy intake of pigs among diets. 


\section{Urinary glucose excretion}

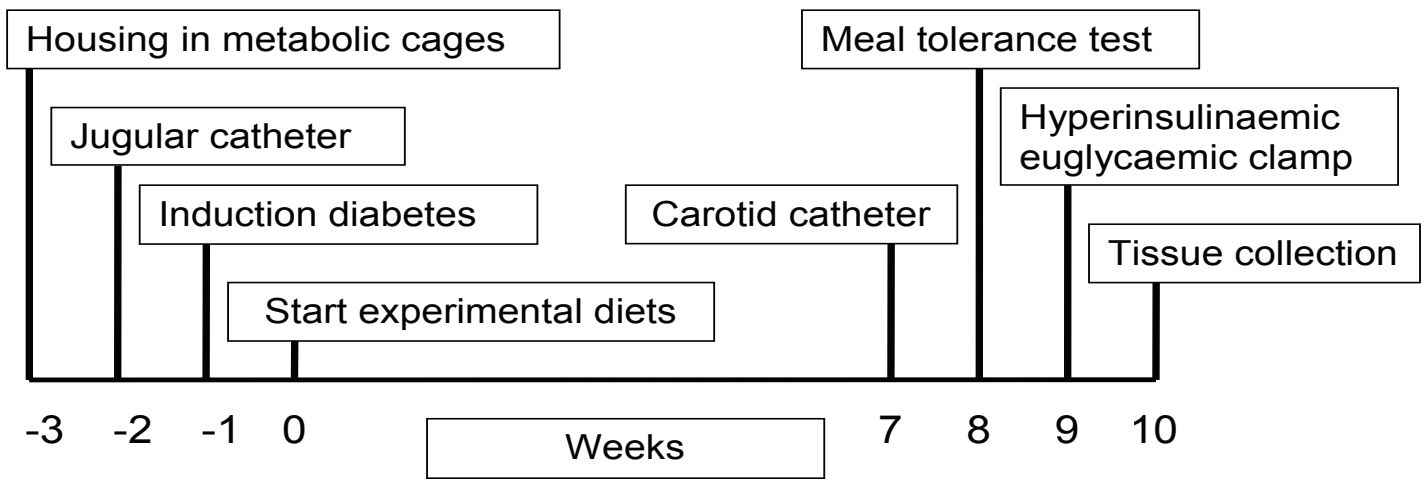

Figure 1 Timeline of the study.

sampling during the hyperinsulinaemic clamp study. Preceding the insulin clamp, overnight fasting blood samples were collected for determining the concentrations of fructosamine, glucagon, cortisol, NEFA, total cholesterol, LDL and HDL cholesterol and background glucose enrichment.

After baseline samples, a prime $(4.8 \mathrm{mg} / \mathrm{kg})$-continuous (0.08 mg.kg $\left.{ }^{-1} \cdot \mathrm{min}^{-1}\right)$ infusion of $6,6{ }^{2} \mathrm{H}_{2}$-glucose was administered for $150 \mathrm{~min}$. After an equilibration time, blood samples were taken at 110, 120, 130, 140 and $150 \mathrm{~min}$ for determination of glucose, $6,6-{ }^{2} \mathrm{H}_{2}$-glucose enrichment (to estimate fasting hepatic glucose production) and insulin. Subsequently, insulin was infused (prime (34 mU/kg)-continuous $\left(2 \mathrm{mU} \cdot \mathrm{kg}^{-1} \cdot \mathrm{min}^{-1}\right)$ ) for 6 hours. A variable infusion of a $33 \%$ D-glucose solution was started to maintain plasma glucose at euglycaemia $(\sim 5 \mathrm{mmol} / \mathrm{L})$. Steady state calculations were carried out during the last 40 minutes of the clamp ( $t=320,330,340,350$ and $360 \mathrm{~min}$ ) and the coefficients of variation for the insulin and glucose concentrations, and for the infusion rate of glucose were determined. During the last 3 hours of the insulin clamp, a prime $(4.8 \mathrm{mg} / \mathrm{kg})$-continuous $\left(0.08 \mathrm{mg} \cdot \mathrm{kg}^{-1} \cdot \mathrm{min}^{-1}\right)$ infusion of $6,6-{ }^{2} \mathrm{H}_{2}$-glucose was superimposed to estimate 1) insulin stimulated whole body glucose uptake (rate of disappearance $=\mathrm{Rd}$ ) and 2) insulin-inhibited hepatic glucose production, as described before [19]. For this purpose blood samples were taken at $\mathrm{t} 320,330,340,350$ and 360 min of the clamp.

Infusates: Insulin (Actrapid $\mathrm{MC}$, porcine monocomponent, Novo, Copenhagen, Denmark), 6,6- ${ }^{2} \mathrm{H}_{2}$-glucose (Cambridge Isotope Laboratories, Inc, MA, USA) and D-glucose (Merck, Darmstadt, Germany) were prepared as sterile solutions and passed through a $0.22 \mu \mathrm{m}$ Millipore filter into sterile containers before use. Insulin was diluted in a saline solution containing pig plasma (final plasma concentration was $3 \%$ ) in order to avoid sticking of insulin to the plastic containers and tubings. $6,6{ }^{-}{ }^{2} \mathrm{H}_{2}-$ glucose was dissolved in a saline solution and D-glucose was dissolved in aqua dest.

\section{Plasma, urine and tissue collection and analyses}

Blood samples collected in heparinised (150 USP. U. Lithium Heparin, $10 \mathrm{~mL}$ Venoject, Terumo, Leuven, Belgium) or EDTA (ethylenediaminetetraacetic acid, (0.47 mol/L EDTA, $10 \mathrm{~mL}$ Venoject, Terumo, Leuven, Belgium) tubes were immediately chilled at $0^{\circ} \mathrm{C}$ on water with ice, and centrifuged at $4^{\circ} \mathrm{C}$ for 10 minutes at $3000 \mathrm{rpm}$. Plasma aliquots were stored at $-80^{\circ} \mathrm{C}$ for later analyses. Urine was quantitatively collected per 24 hours in buckets containing 0.5 grams Halamid-d (sodium-ptoluenesulfonchloramide, Akzo Nobel Chemicals, Amersfoort, The Netherlands) to prevent microbial breakdown of glucose. Urine samples were stored at $-20^{\circ} \mathrm{C}$ for later glucose analyses. Muscle (m. iliopsoasis) and liver were snap-frozen in liquid nitrogen and stored at $-80^{\circ} \mathrm{C}$. Abdominal aorta was fixed in a $4 \%$ paraformaldehyde solution.

Plasma samples for determination of $6,6-{ }^{2} \mathrm{H}_{2}$-glucose enrichment were analyzed as described previously [19]. In short, glucose was extracted from plasma, derivatised, and injected into a gas chromatograph/mass spectrometer system (HP 6890 series GC system and 5973 Mass Selective Detector, Palo Alto, CA, USA). Separation was achieved on a J\&W scientific DB 17 capillary column $(30 \mathrm{~m} \times 0.25 \mathrm{~mm} \times 0.25 \mu \mathrm{m}$; Agilent Technologies Nederland BV, Amstelveen, The Netherlands). Isotopic enrichment was calculated as tracer-to- tracee ratio after subtracting the isotopic enrichment of a background plasma sample. An aliquot of the $6,6-{ }^{2} \mathrm{H}_{2}$-glucose infusate was analyzed for the isotope concentration to calculate the actual infusion rate for each infusion experiment. 
Plasma glucose was analyzed with the Glucose liquiUV mono kit (Human, Wiesbaden, Germany), plasma nonesterified fatty acids were analyzed with the WAKO kit (Neuss, Germany) and plasma triglycerides with a kit from Human (Wiesbaden, Germany). Total, LDL and HDL cholesterol concentrations in plasma were determined with liquicolor kits (Human, Wiesbaden, Germany) and VLDL cholesterol was calculated as total cholesterol minus LDL and HDL cholesterol. Plasma insulin concentration was measured using a Delfia assay (test kit by Perkin Elmer Life Sciences Trust by Wallac Oy, Turku, Finland). This specific pig insulin assay was validated using pig insulin standards, as indicated before [30]. Plasma glucagon was measured with a kit from Euro-Diagnostica (Arnhem, The Netherlands), plasma cortisol with the Count-A-Count Cortisol kit (DPC, Los Angeles, USA) and fructosamine by a kit from Spinreact (Sant Esteve De Bas, Spain). Plasma C-reactive protein (CRP), interleukin-6 (IL-6) and tumor necrosis factor alpha (TNF- $\alpha$ ) were analyzed with kits (CRP-hs, Human, Wiesbaden, Germany; Haptoglobin, Instruchemie, Delfzijl, The Netherlands; SW Interleukin 6, IBL, Hamburg, Germany and SW TNF-alpha Elisa Kit, Biosource Int, Camarillo, USA), respectively.

Ketones (acetoacetic acid) were determined in fresh urine by a reagent strip test (Ketostix, Bayer Diagnostics, Mijdrecht, The Netherlands).

Triglyceride concentrations in muscle and liver samples were determined with the same kit as used for the plasma samples, after saponification with an alkalin alcohol solution as previously described [31].

Aortic fatty streaks, as a marker of early atherosclerosis [22,24], (AHA class 2 lesion [32]), were quantified with use of Sudan IV fat stain in sections of the abdominal aorta ranging from the bifurcation of the renal arteries to the bifurcation of the iliac arteries. The stained aortas were then photographed and analyzed with a microscopy image analysis system (Clemex technologies Inc., Quebec, Canada) as ratio of stained area to total area.

\section{Statistical analyses}

Results are expressed as means \pm SEM and the criterion of statistical significance was set at $\mathrm{p}<0.05$. The data were subjected to the analysis of variance procedure (ANOVA) (for repeated measurements when applicable) followed by the unpaired or paired student's t-test of Genstat 5 [33] for determination of differences between or within the three dietary groups, respectively.

\section{Results}

\section{Body composition}

Final body weights were comparable among SFC, UF and $S$ pigs indicating that average food intake and urinary glucose excretion were in balance during the course of the study per diet group (Table 2). However, liver weights and triglyceride concentrations were higher $(\mathrm{p}<0.01)$ in SFC pigs compared to UF and S pigs. Triglyceride concentration in muscle was highest $(\mathrm{p}<0.01)$ in SFC pigs, intermediate in UF and lowest in S pigs. Retroperitoneal fat depot weight was intermediate in SFC (260 $\pm 72 \mathrm{~g})$, lowest in $\mathrm{S}(135 \pm 51 \mathrm{~g})$ and highest $(\mathrm{p}<0.05)$ in UF $(571$ \pm 95) pigs.

\section{Metabolic control}

At the end of the dietary intervention, fasting plasma insulin, glucagon, glucose, fructosamine and triglyceride concentrations were similar among all diabetic pigs (Tables 3 and 4). Fasting plasma total cholesterol, HDL, LDL and VLDL concentrations were higher $(\mathrm{p}<0.01)$ in SFC pigs compared to UF and S pigs. The ratio of HDL/LDL cholesterol was unchanged but the ratio of HDL/total cholesterol was reduced $(\mathrm{p}<0.05)$ in SFC and UF pigs compared to $S$ pigs (Table 4). Fasting plasma NEFA concentrations were highest $(\mathrm{p}<0.05)$ in SFC pigs, intermediate in UF pigs and lowest $\mathrm{S}$ pigs (Table 4). Fasting hepatic glucose production, insulin-inhibited hepatic glucose production and insulin-stimulated whole body glucose uptake were similar among diabetic pigs (Table 3). Coefficients of variation of clamp plasma glucose, plasma insulin and glucose infusion rate in SFC versus UF versus $S$ pigs were $5 \pm$ 2 versus $7 \pm 3$ versus $3 \pm 1 \%, 11 \pm 5$ versus $7 \pm 2$ versus $8 \pm 3 \%$ and $2 \pm 1$ versus $3 \pm 1$ versus $2 \pm 1 \%$, respectively. The postprandial response area under the curves (0-4 h or $0-8 \mathrm{~h}$ ) for glucose but not for insulin and triglyceride responses were intermediate in SFC $(617 \pm 144$ or $471 \pm$ 122), lowest ( $<<0.05)$ in UF $(378 \pm 157$ or $292 \pm 133)$ and highest in S pigs (925 \pm 139 or $724 \pm 92$ (Figures 2 and 3).

\section{Inflammation}

The fasting plasma concentrations of cortisol, haptoglobin, IL- 6 and TNF-a were not statistically different between the diet groups (Table 4). By contrast, both fasting and postprandial plasma $\mathrm{C}$-reactive protein (CRP) concentrations and meal-induced CRP responses $(\Delta)$ were higher $(\mathrm{p}<0.05)$ in SFC pigs compared to UF pigs but not always higher compared to $\mathrm{S}$ pigs, i.e. fasting plasma CRP concentration was similar in SFC and $S$ pigs (Figure 4).

\section{Atherosclerosis and blood pressure}

The surface area of aorta fatty streaks was higher $(\mathrm{p}<$ 0.001 ) in SFC pigs compared to UF and S pigs (Table 2). Visualization of the fatty streaks in the abdominal aortas of the three groups of pigs is presented in Figure 5. In SFC pigs, a positive correlation between surface area of aorta fatty streaks and postprandial plasma CRP concentration was observed $\left(\mathrm{R}^{2}=0.95, \mathrm{p}<0.001\right)$ (Figure 6). Mean arterial, systolic and diastolic blood pressures were 
Table 2 Food intake, urinary glucose excretion, final body weights and tissue data of diabetic pigs fed saturated fat/ cholesterol or unsaturated fat or starch enriched diets

\begin{tabular}{llcc}
\hline & Saturated fat plus cholesterol diet & Unsaturated fat diet & Starch diet \\
\hline Factual average food intake (MJ/day) & $23.9 \pm 1.3$ & $25.0 \pm 2.0$ & $27.7 \pm 0.9$ \\
Average urinary glucose excretion (MJ/day) & $8.5 \pm 1.0^{\mathrm{A}}$ & $9.1 \pm 1.1^{\mathrm{A}}$ & $15.8 \pm 2.1^{\mathrm{B}}$ \\
Final body weight $(\mathbf{k g})$ & $41 \pm 3$ & $45 \pm 5$ & $48 \pm 7$ \\
Liver weight $(\mathbf{k g})$ & $1.47 \pm 0.08^{\mathrm{A}}$ & $1.12 \pm 0.03^{\mathrm{B}}$ & $1.11 \pm 0.03^{\mathrm{B}}$ \\
Liver triglyceride concentration $(\mathbf{g} / \mathbf{k g})$ & $49 \pm 11^{\mathrm{A}}$ & $27 \pm 1^{\mathrm{B}}$ & $21 \pm 3^{\mathrm{B}}$ \\
Muscle triglyceride concentration $(\mathbf{g} / \mathbf{k g})$ & $21 \pm 4^{\mathrm{A}}$ & $13 \pm 3^{\mathrm{AB}}$ & $8 \pm 1^{\mathrm{B}}$ \\
Retroperitoneal fat weight $(\mathbf{g})$ & $260 \pm 72^{\mathrm{AB}}$ & $571 \pm 95^{\mathrm{A}}$ & $135 \pm 51^{\mathrm{B}}$ \\
Surface area aorta fatty steaks (\%) & $17.9 \pm 4.4^{\mathrm{A}}$ & $0.03 \pm 0.02^{\mathrm{B}}$ & $0.14 \pm 0.07^{\mathrm{B}}$ \\
\hline
\end{tabular}

$\mathrm{A}, \mathrm{B}$, data with different superscripts in the same row differ at $\mathrm{p}<0.05$.

not statistically different between the diet groups (Table 5).

\section{Discussion}

\section{Main findings}

Pigs on dietary SFC showed a more atherogenic plasma profile with higher plasma NEFA concentrations, higher liver weights and liver triglyceride concentrations, and increased aorta fatty streak area compared to pigs on dietary UF and S. The postprandial glucose, but not insulin and triglyceride responses were intermediate in SFC pigs, lowest in UF pigs and highest in S pigs, whereas hepatic and whole body insulin sensitivities for glucose metabolism were not significantly affected by the diets. This indicates that the postprandial glucose intolerance of S pigs compared to SFC and UF pigs is caused by an increased systemic influx of dietary glucose after starch digestion and not by insulin resistance. The mechanisms behind the relative postprandial glucose intolerance in SFC pigs compared to UF pigs are unknown. However, several non-significant factors may contribute to the difference in postprandial glucose tolerance. Fasting and insulin-inhibited hepatic glucose production during the clamp were elevated by $16 \%(\mathrm{p}=\mathrm{NS})$ and $50 \%(\mathrm{p}=\mathrm{NS})$ and early (30 $\mathrm{min})$ postprandial insulin secretion was 2fold reduced ( $\mathrm{p}=\mathrm{NS}$ ) in SFC pigs compared to UF pigs.
For the latter, it has been suggested that the degree of saturation of fatty acids may have a negative influence on insulin release by beta-cells in vitro [34]. Taken together, these factors may add-up and act in concert to both impair non-insulin-dependent and insulin-dependent glucose tolerance in SFC pigs compared to UF pigs.

With respect to body composition, SFC pigs showed increased muscle, liver and aorta fat deposits and a reduced amount of retroperitoneal fat. The latter nonectopic depot of adipose tissue was largest in UF pigs, indicating that body composition is most favourably affected by the UF diet compared to the SFC diet in this non-obese diabetic pig model. The UF diet is mainly stored in adipose tissue and to a lesser extent in organs and the vascular system. By contrast, the $\mathrm{S}$ pigs showed the lowest muscle and liver fat deposits and a low amount of retroperitoneal fat. This indicates that energy storage in the form of fat is low from dietary $\mathrm{S}$, both in adipose and non-adipose tissue. The baseline markers of systemic inflammation tended to be higher in SFC pigs, but only baseline and postprandial CRP concentrations reached levels of statistical significance. A strong correlation was observed between postprandial plasma CRP and aorta fatty streak area $\left(R^{2}=0.95, p<0.001\right)$, suggesting that postprandial CRP is a biomarker for atherosclerosis in this diabetic pig model. This is one of the few pieces of

Table 3 Fasting hepatic glucose production, insulin-stimulated whole body glucose uptake, insulin-inhibited hepatic glucose production and plasma concentrations of metabolites and insulin in diabetic pigs fed saturated fat/cholesterol or unsaturated fat or starch enriched diets

\begin{tabular}{|c|c|c|c|}
\hline & Saturated fat plus cholesterol diet & Unsaturated fat diet & Starch diet \\
\hline Fasting plasma fructosamine ( $\mu \mathrm{mol} / \mathrm{L})$ & $449 \pm 25$ & $494 \pm 62$ & $558 \pm 103$ \\
\hline Fasting plasma glucose (mmol/L) & $12.4 \pm 0.4$ & $14.4 \pm 0.7$ & $12.7 \pm 1.6$ \\
\hline Fasting plasma insulin (pmol/L) & $23 \pm 7$ & $26 \pm 7$ & $22 \pm 4$ \\
\hline Fasting hepatic glucose production $\left(\mathrm{mg} \cdot \mathrm{kg}^{-1} \cdot \mathrm{min}^{-1}\right)$ & $7.4 \pm 0.8$ & $6.4 \pm 0.5$ & $8.2 \pm 2.0$ \\
\hline Clamp plasma glucose (steady state, mmol/L) & $5.7 \pm 0.2$ & $5.4 \pm 0.2$ & $5.4 \pm 0.2$ \\
\hline Clamp plasma insulin (steady state, pmol/L) & $320 \pm 27$ & $409 \pm 33$ & $327 \pm 33$ \\
\hline Insulin-stimulated whole body glucose uptake $\left(\mathrm{mg} \cdot \mathrm{kg}^{-1} \cdot \mathrm{min}^{-1}\right)$ & $10.0 \pm 2.3$ & $9.5 \pm 2.1$ & $10.8 \pm 2.8$ \\
\hline $\begin{array}{l}\text { Insulin-inhibited hepatic glucose production } \\
\left(\mathrm{mg} \cdot \mathrm{kg}^{-1} \cdot \mathrm{min}^{-1}\right)\end{array}$ & $1.8 \pm 0.2$ & $1.2 \pm 0.3$ & $1.8 \pm 0.1$ \\
\hline
\end{tabular}


Table 4 Fasting plasma concentrations of lipid metabolites, hormones and inflammatory markers in diabetic pigs fed saturated fat/cholesterol or unsaturated fat or starch enriched diets

\begin{tabular}{llcc}
\hline & Saturated fat plus cholesterol diet & Unsaturated fat diet & Starch diet \\
\hline NEFA (mmol/L) & $1.09 \pm 0.17^{\mathrm{A}}$ & $0.80 \pm 0.14^{\mathrm{AB}}$ & $0.58 \pm 0.14^{\mathrm{B}}$ \\
Triglycerides (mmol/L) & $0.58 \pm 0.17$ & $0.51 \pm 0.05$ & $0.43 \pm 0.11$ \\
Total cholesterol (mmol/L) & $9.9 \pm 1.2^{\mathrm{A}}$ & $2.0 \pm 0.1^{\mathrm{B}}$ & $1.7 \pm 0.2^{\mathrm{B}}$ \\
HDL cholesterol (mmol/L) & $2.1 \pm 0.2^{\mathrm{A}}$ & $0.4 \pm 0.0^{\mathrm{B}}$ & $0.5 \pm 0.0^{\mathrm{B}}$ \\
LDL cholesterol (mmol/L) & $3.3 \pm 0.3^{\mathrm{A}}$ & $1.3 \pm 0.1^{\mathrm{B}}$ & $1.1^{\mathrm{B}} \pm 0.1^{\mathrm{B}}$ \\
VLDL cholesterol (mmol/L) & $4.5 \pm 0.8^{\mathrm{A}}$ & $0.2 \pm 0.1^{\mathrm{B}}$ & $0.1 \pm 0.0^{\mathrm{B}}$ \\
Ratio HDL/LDL cholesterol & $0.64 \pm 0.08$ & $0.35 \pm 0.05$ & $0.46 \pm 0.03$ \\
Ratio HDL/total cholesterol & $0.21 \pm 0.01^{\mathrm{A}}$ & $0.23 \pm 0.02^{\mathrm{A}}$ & $0.29 \pm 0.01^{\mathrm{B}}$ \\
Glucagon (pmol/L) & $131 \pm 25$ & $114 \pm 35$ & $83 \pm 10$ \\
Cortisol (nmol/L) & $334 \pm 44$ & $284 \pm 69$ & $262 \pm 50$ \\
Haptoglobin (pg/mL) & $251 \pm 132$ & $394 \pm 100$ & $236 \pm 52$ \\
IL-6 $(\mathbf{p g} / \mathbf{m L})$ & $2224 \pm 1102$ & $818 \pm 664$ & $459 \pm 270$ \\
TNF- $\boldsymbol{\alpha}$ (pg/mL) & $610 \pm 289$ & $394 \pm 248$ & $384 \pm 135$ \\
\hline
\end{tabular}

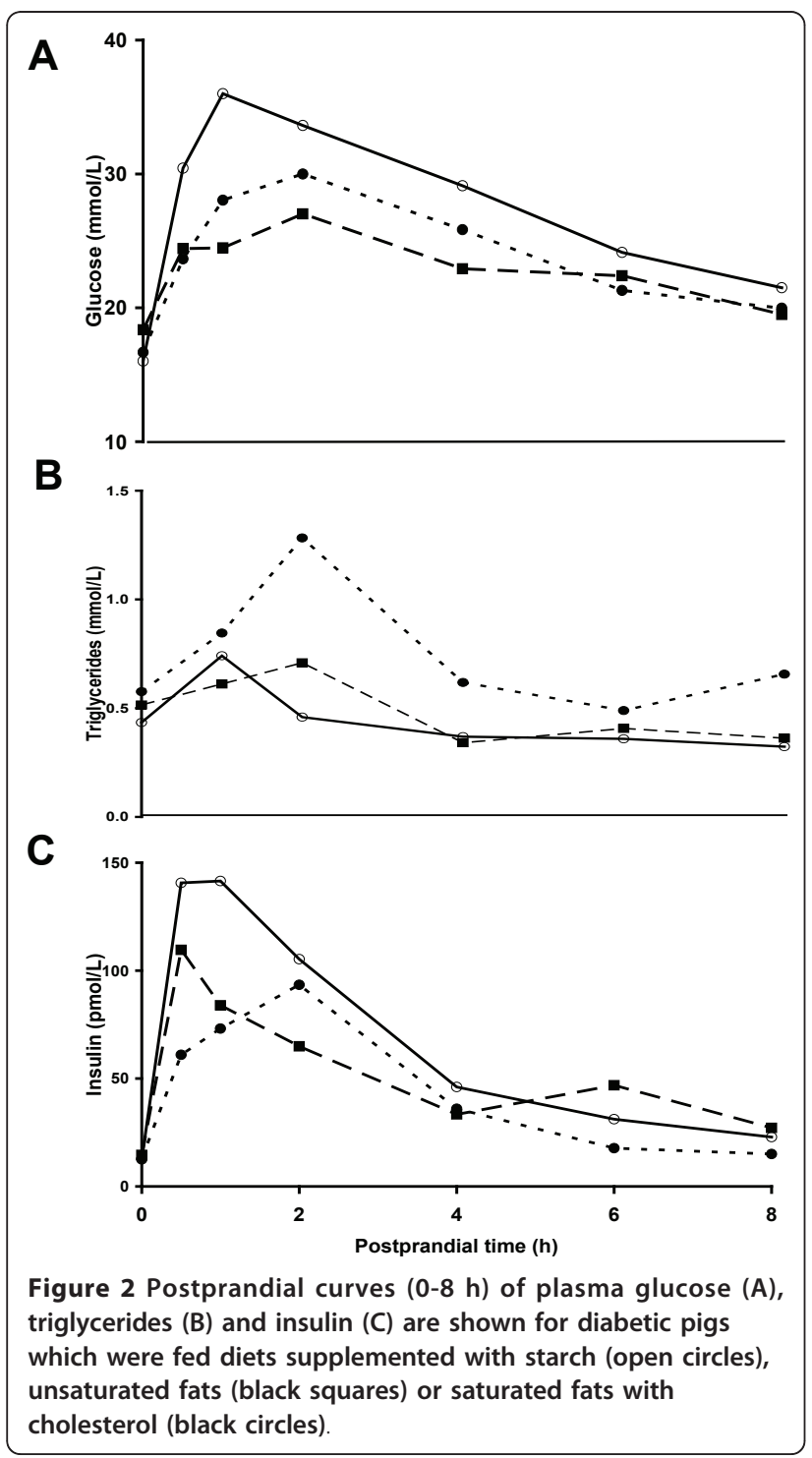

evidence that the inflammatory marker CRP is secondary to the atheromatous process itself.

Taken together, these main findings indicate that dietary saturated fat/cholesterol induces CRP associated early atherosclerosis and ectopic fat deposition whereas eucaloric unsaturated fat or starch do not induce these abnormalities and unsaturated fat shows beneficial effects on postprandial glycaemia in diabetic pigs.

\section{Insulin resistance}

After a 10-week intervention study, dietary composition had no significant effect on insulin sensitivity in diabetic pigs. This is in line with a 2-week intervention study in type 2 diabetic patients [35]. In non-diabetic rodents however, it is widely accepted that long-term feeding of dietary saturated fats induces insulin resistance whereas unsaturated fats increase insulin sensitivity [6]. This discrepancy may be caused by the fact that insulin resistance is already a prominent feature of diabetic humans [27] and pigs [19] and any modest dietary effect on insulin sensitivity does not come to expression in insulin resistant individuals. For example, both liver [6] and skeletal muscle [36] triglyceride concentrations have been shown to affect insulin sensitivity but in the present study, the diet-induced 2-fold variation in liver and skeletal muscle triglyceride concentrations is insufficient to further modulate insulin resistance in diabetic pigs.

\section{Inflammation}

Fasting plasma concentrations of the acute phase protein CRP were higher in diabetic pigs which were fed the SFC diet compared to the UF diet but not to the $S$ diet. This underlines the anti-inflammatory effect of dietary UF $[37,38]$. The pro-inflammatory effect of a diet rich in saturated fats and cholesterol has been shown before in 


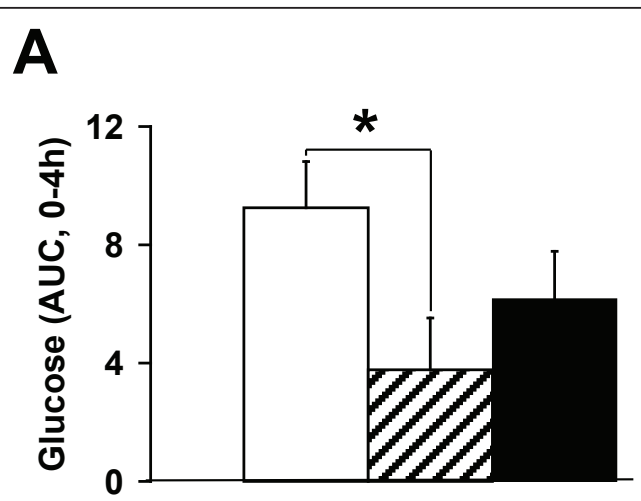

B

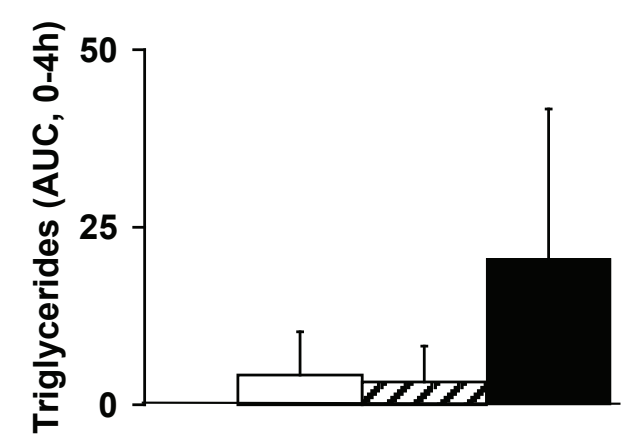

C

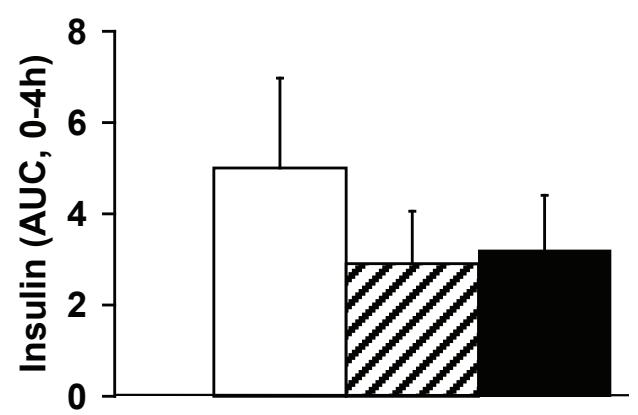

Figure 3 The postprandial response areas under the curve ( $\Delta 0-4$ h) are depicted for plasma glucose (A), triglycerides (B) and insulin (C) for supplemental starch (open bars), unsaturated fats (striped bars) or saturated fats with cholesterol (black bars). Means \pm SEM. ${ }^{*} p<0.05$.

non-diabetic humans $[8,10]$ and in non-diabetic pigs $[39,40]$. In our study, postprandial plasma CRP, but not haptoglobin, IL- 6 or TNF- $\alpha$, positively correlated with the severity of beginning atherosclerosis. It seems therefore that postprandial CRP concentrations, which were increased 2-fold compared to fasting concentrations, react strongly to vascular damage and/or atherosclerosis [41]. Indeed, CRP has been proposed as a putative clinical biomarker for atherosclerosis $[42,43]$ serving a possible

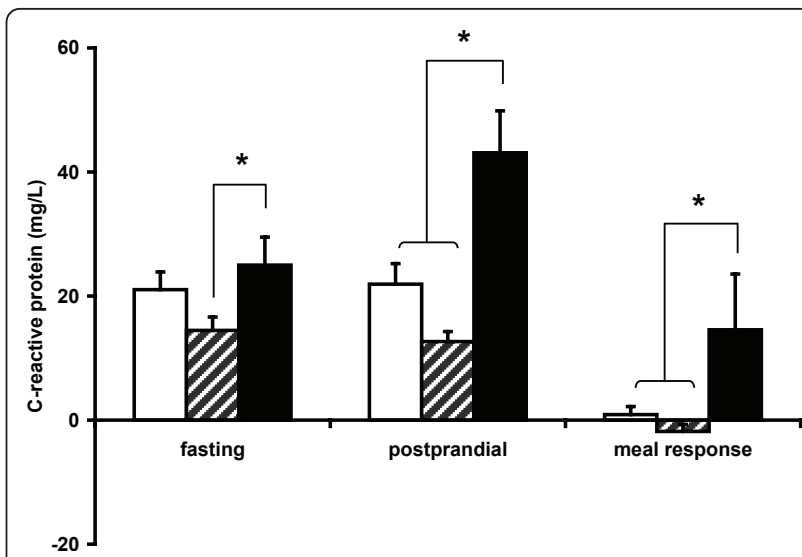

Figure 4 Overnight fasting and postprandial $(3 \mathrm{~h})$ plasma Creactive protein (CRP) concentrations and the meal response over fasting $(\Delta)$ are depicted for diabetic pigs which were fed diets supplemented with starch (open bars), unsaturated fats (striped bars) or saturated fats with cholesterol (black bars). Means \pm SEM. ${ }^{*} p<0.05$.

protective role in the atherogenic process [44]. In diabetic pigs which were fed a diet rich in UF, no increase in postprandial CRP was observed. This corresponds with the absence of atherosclerosis in these diabetic pigs. The beneficial mechanism of action of UF, but not SFC, may be related to the affinity to bind to the nuclear peroxisome proliferator-activated receptor (PPAR), the same pathway which is activated by the anti-diabetic drug thiazolidinedione (TZD) [27,45-47]. Therefore, dietary UF can be regarded as a therapeutic agent to prevent some of the abnormalities of type 2 diabetes.

\section{Diabetic pig model}

Fasting plasma insulin $(\sim 25 \mathrm{pmol} / \mathrm{L})$, glucose $(\sim 13$ $\mathrm{mmol} / \mathrm{L})$ and triglyceride $(\sim 0.5 \mathrm{mmol} / \mathrm{L})$ concentrations and a positive energy balance (body weight gain of $\sim 1.5 \mathrm{~kg} /$ week) without the occurrence of ketosis indicated a mild form of diabetes in the pigs. In a previous paper we argued that the present insulin resistant pig model resembled type 2 diabetes [19]. In addition to these observations, we now showed that, after streptozotocin treatment, the residual beta-cells of the pancreas were able to increase insulin secretion $\sim 5-7$ fold upon a meal-challenge. This indicates that a substantial endogenous insulin secretion capacity is still present in this diabetic pig model.

\section{Conclusion}

When comparing dietary SFC, UF and S, dietary SFC induces CRP-associated early atherosclerosis and ectopic fat deposition whereas isoenergetic UF shows beneficial effects on postprandial glycaemia, inflammation and body composition in diabetic pigs. 

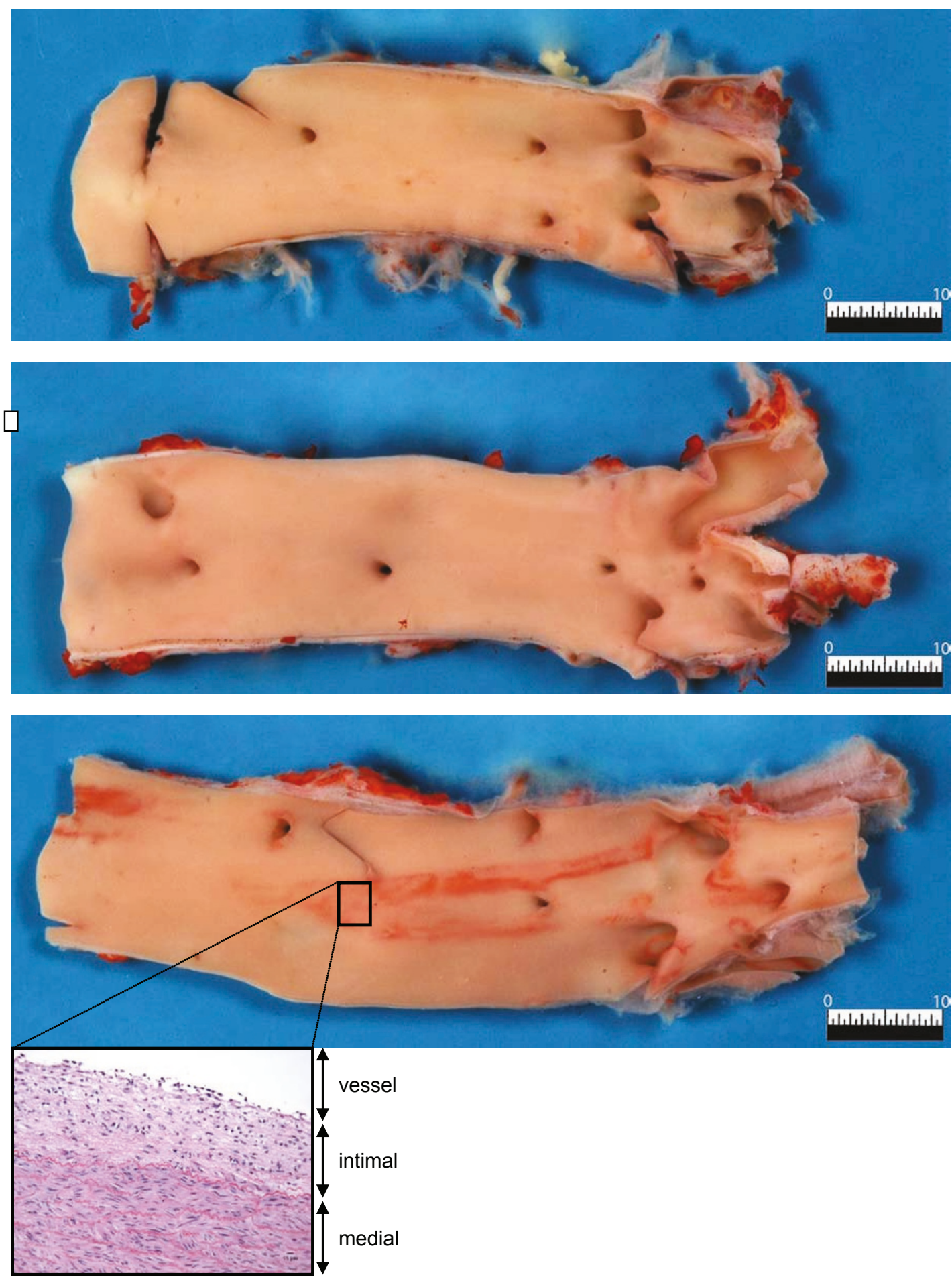

Figure 5 Images of typical examples of abdominal aorta Sudan IV fat staining of diabetic pigs, which were fed diets supplemented with starch (top picture), unsaturated fats (middle), or saturated fats with cholesterol (bottom). Red intra-luminal staining indicates presence of fatty streaks. Insert in bottom picture shows histological detail (hematoxylin-eosin staining) of fatty streak $(4 \times$ magnification). The intimal area of this part of the vessel wall consists of multiple cellular layers with empty little spaces where fat was deposited. 


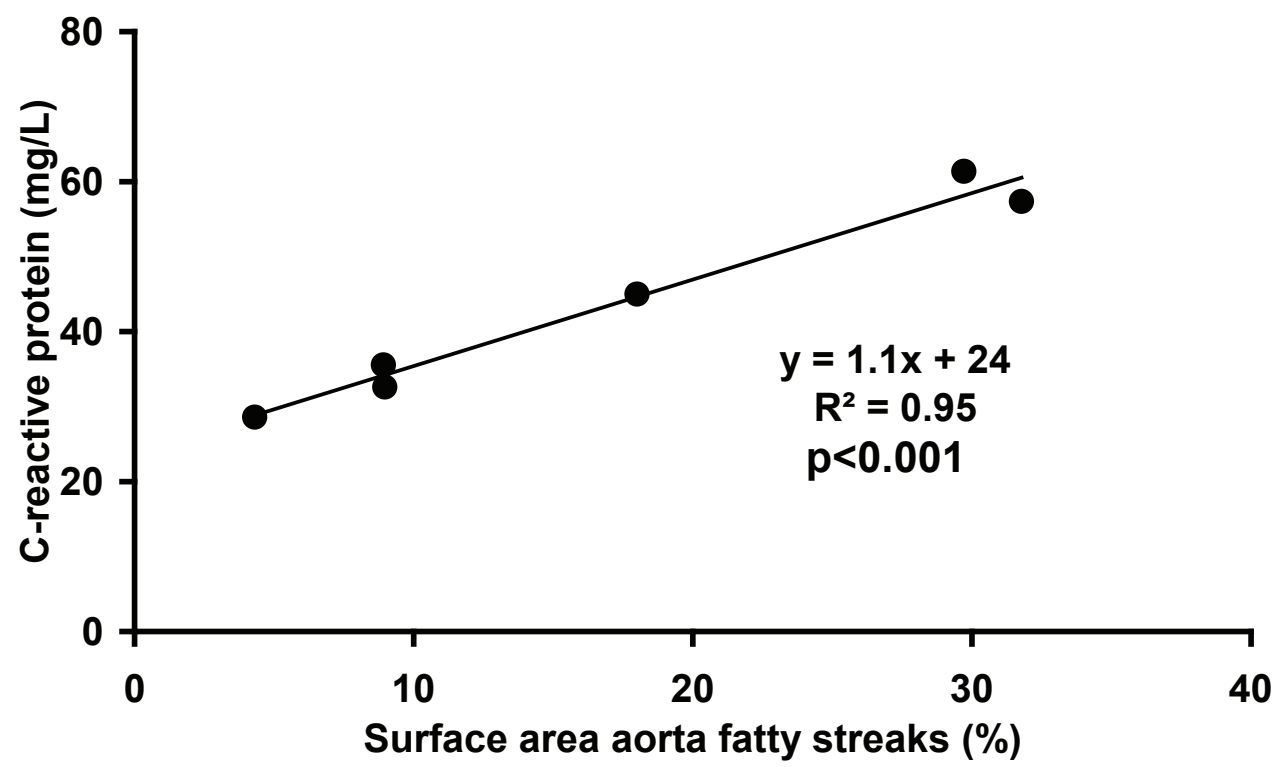

Figure 6 Correlation between plasma C-reactive protein (CRP) concentrations and the surface area of abdominal aorta fatty streaks $(\%)$ in diabetic pigs which were fed a diet supplemented with saturated fats and cholesterol. $\left(R^{2}=0.95, p<0.001\right)$.

Table 5 Blood pressure and heart rate in diabetic pigs fed saturated fat/cholesterol or unsaturated fat or starch enriched diets

\begin{tabular}{llcc}
\hline & Saturated fat plus cholesterol diet & Unsaturated fat diet & Starch diet \\
\hline $\begin{array}{l}\text { Mean arterial pressure } \\
(\mathbf{m m H g})\end{array}$ & $113 \pm 14$ & $96 \pm 5$ & $96 \pm 4$ \\
Systolic pressure $(\mathbf{m m H g})$ & $139 \pm 18$ & $117 \pm 5$ & $116 \pm 5$ \\
Diastolic pressure $(\mathbf{m m H g})$ & $97 \pm 13$ & $78 \pm 5$ & $78 \pm 4$ \\
Heart rate (beats per minute) & $109 \pm 10$ & $92 \pm 21$ & $109 \pm 22$ \\
\hline
\end{tabular}

\section{Abbreviations}

AUC: area under the curve; CRP: C-reactive protein; ME: metabolizable energy; NEFA: non-esterified fatty acids; PPAR: peroxisome proliferatoractivated receptor; PUFA: polyunsaturated fatty acids; S: starch; SFC: saturated fat with cholesterol; STZ: streptozotocin; TZD: thiazolidinedione; UF: unsaturated fat.

\section{Acknowledgements and Funding}

This study is dedicated to our beloved friend and colleague WJG, deceased. This study was supported by the Ministry of Agriculture, Nature and Food Quality of The Netherlands. We thank Z. Mroz for the excellent surgical assistance.

\section{Author details}

${ }^{1}$ BioMedical Research of Wageningen University and Research Center, Lelystad, The Netherlands. ${ }^{2}$ Department of Animal Sciences, Adaptation Physiology Group of Wageningen University, Wageningen, The Netherlands. ${ }^{3}$ Clinical Chemistry, Laboratory of Endocrinology, Academic Medical Center, Amsterdam, The Netherlands. ${ }^{4}$ Endocrinology \& Metabolism, Academic Medical Center, Amsterdam, The Netherlands. ${ }^{5}$ Experimental Cardiology, Erasmus Medical Center, Rotterdam, The Netherlands. ${ }^{6}$ ICIN-KNAW, Utrecht, The Netherlands.

\section{Authors' contributions}

SJK was the principal investigator, involved in designing the study and writing the manuscript. RD coordinated the study and performed statistical analyses. MTA, HS and MJS were involved in developing the clamp technique in pigs and performing the stable isotope measurements and writing parts of the manuscript. $\mathrm{HMMB}, \mathrm{MH}$ and WJG were involved in the cardiovascular measurements and writing parts of the manuscript. All authors participated in writing the final version of the manuscript.

\section{Competing interests}

The authors declare that they have no competing interests.

Received: 18 April 2011 Accepted: 14 July 2011 Published: 14 July 2011

\section{References}

1. Din JN, Newby DE, Flapan AD: Omega 3 fatty acids and cardiovascular disease-fishing for a natural treatment. Br Med J 2004, 328:30-35.

2. Esposito K, Marfella R, Ciotola M, Di Palo C, Giugliano F, Giugliano G, D'Armiento M, D'Andrea F, Giugliano D: Effect of a Mediterranean-style diet on endothelial dysfunction and markers of vascular inflammation in the metabolic syndrome. J Am Med Assoc 2004, 292:1440-1446.

3. Esposito K, Giugliano D: Diet and inflammation: a link to metabolic and cardiovascular diseases. Eur Heart J 2006, 27:15-20.

4. Rallidis LS, Paschos G, Liakos GK, Velissaridou AH, Anastasiadis G, Zampelas A: Dietary a-linolenic acid decreases C-reactive protein, serum amyloid A and interleukin- 6 in dyslipidaemic patients. Atherosclerosis 2003, 167:237-242

5. Jönsson $T$, Ahrén B, Pacini G, Sundler F, Wierup N, Steen S, Sjöberg T, Ugander M, Göransson L, Lindeberg S: A Paleolithic diet confers higher insulin sensitivity, lower $C$-reactive protein and lower blood pressure than a cereal-based diet in domestic pigs. BMC Nutrition \& Metabolism 2006, 3:39. 
6. Buettner R, Parhofer KG, Woenckhaus M, Wrede CE, Kunz-Schughart LA, Schölmerich J, Bollheimer LC: Defining high-fat-diet rat models: metabolic and molecular effects of different fat types. J Mol Endo 2006, 36:485-501.

7. Sinitskaya N, Gourmelen S, Schuster-Klein C, Guardiola-lemaitre B, Pévet P, Challet E: Increasing the fat-to-carbohydrate ratio in a high-fat diet prevents the development of obesity but not a prediabetic state in rats. Clinical Science 2007, 113:417-425.

8. King DE, Egan BM, Geesey ME: Relation of dietary fat and fiber to elevation of C-reactive protein. Am J Cardiol 2003, 92:1335-1339.

9. Storlien LH, Baur LA, Kriketos AD, Pan DA, Cooney GJ, Jenkins AB, Calvert GD, Campbell LV: Dietary fats and insulin action. Diabetologia 1996, 39:621-631.

10. Tannock LR, O'Brien KD, Knopp RH, Retzlaff B, Fish B, Wener MH, Kahn SE, Chait A: Cholesterol feeding increases C-reactive protein and serum amyloid A levels in lean insulin-sensitive subjects. Circulation 2005, 111:3058-3062.

11. Due A, Toubro S, Stender S, Skov AR, Astrup A: The effect of diets high in protein or carbohydrate on inflammatory markers in overweight subjects. Diabetes Obesity Metabolism 2005, 7:223-229.

12. Garg A, Grundy SM, Koffler M: Effect of high carbohydrate intake on hyperglycemia, islet function, and plasma lipoproteins in NIDDM. Diabetes Care 1992, 15:1572-1579.

13. Nappo F, Esposito K, Cioffi M, Giugliano G, Molinari AM, Paolisso G, Marfella R, Giugliano D: Postprandial endothelial activation in healthy subjects and in type 2 diabetic patients: role of fat and carbohydrate meals. J Am Coll Cardiol 2002, 39:1145-1150.

14. Wolever TMS: The Glycaemic Index A Physiological Classification of Dietary Carbohydrate Oxfordshire, UK: CABl; 2006.

15. Jönsson T, Granfeldt $Y$, Ahrén B, Branell U-C, Pålsson G, Hansson A, Söderström M, Lindeberg S: Beneficial effects of a Paleolithic diet on cardiovascular risk factors in type 2 diabetes: a randomized cross-over pilot study. Cardiovasc Diabetol 2009, 8:35.

16. Sabaté E: Adherence to long-term therapies: evidence for action Geneva, Switzerland: World Health Organization; 2003.

17. Afman L, Müller M: Nutrigenomics: from molecular nutrition to prevention of disease. J Am Diet Assoc 2006, 106:569-576.

18. Müller M, Kersten S: Nutrigenomics: goals and strategies. Nature Reviews Genetics 2003, 4:315-322

19. Koopmans SJ, Mroz Z, Dekker R, Corbijn H, Ackermans M, Sauerwein H: Association of insulin resistance with hyperglycemia in streptozotocindiabetic pigs. Effects of metformin at isoenergetic feeding in a type 2like diabetic pig model. Metabolism 2006, 55:960-971.

20. Miller ER, Ullrey DE: The pig as a model for human nutrition. Ann Rev Nutr 1987, 7:361-382.

21. Moughan PJ, Cranwell PD, Darragh AJ, Rowan AM: The domestic pig as a model animal for studying digestion in humans. Sixth International Symposium on digestive physiology in pigs II 1994, 389-396.

22. Dixon JL, Stoops JD, Parker JL, Laughlin MH, Weisman GA, Sturek M: Dyslipidemia and vascular dysfunction in diabetic pigs fed an atherogenic diet. Arterioscler Thromb Vasc Biol 1999, 19:2981-2992.

23. Fricker J: The pig: a new model of diabetic atherosclerosis. DDT 2001, 6:921-922.

24. Gerrity RG, Natarajan R, Nadler JL, Kimsey T: Diabetes-induced accelerated atherosclerosis in swine. Diabetes 2001, 50:1654-1665.

25. Zhang L, Zalewski A, Liu Y, Mazurek T, Cowan S, Martin JL, Hofmann SM, Vlassara $H$, Shi $Y$ : Diabetes-induced oxidative stress and low-grade inflammation in porcine coronary arteries. Circulation 2003, 108:472-478.

26. Festa A, D'Agostino R, Howard G, Tracy RP, Haffner SM: Chronic subclinical inflammation as part of the insulin resistance syndrome. Circulation 2000, 102:42-47.

27. Bays $H$, Mandarino L, DeFronzo RA: Role of the adipocyte, free fatty acids, and ectopic fat in pathogenesis of type 2 diabetes mellitus: peroxisomal proliferator-activated receptor agonists provide a rational therapeutic approach. J Clin Endo Metab 2004, 89:463-478.

28. Kilkenny C, Browne WJ, Cuthill IC, Emerson M, Altman DG: Improving bioscience research reporting: the ARRIVE guidelines for reporting animal research. PLOS Biol 2010, 8(6):e1000412..

29. Koopmans SJ, Van der Meulen J, Dekker R, Corbijn H, Mroz Z: Diurnal variation in insulin-stimulated systemic glucose and amino acid utilization in pigs fed with identical meals at 12-hour intervals. Horm Metab Res 2006, 38:607-613.
30. Koopmans SJ, Mroz Z, Dekker R, Corbijn H, Wijdenes J, Van der Crabben S, Ackermans M, Sauerwein HP: Insulin-stimulated net utilization of plasma glucose and amino acids in growing pigs. In Progress in research on energy and protein metabolism Edited by: Souffrant WB, and Metges CC 2003, 109:197-200

31. Eggstein M, Kreuz FH: Eine neue bestimmung der Neutralfette im Blutserum und Gewebe. Klin Wochenschr 1966, 44:262-267.

32. Stary HC, Chandler AB, Glagov S, Guyton JR, Insull W Jr, Rosenfeld ME, Schaffer SA, Schwartz CJ, Wagner WD, Wissler RW: A definition of initial, fatty streak, and intermediate lesions of atherosclerosis. Circulation 1994, 89:2462-78.

33. Payne RW, Lane PW, Ainsley AE: Genstat 5 Reference Manual Oxford, UK: Oxford University Press; 1987

34. Opara EC, Garfinkel M, Hubbard VS, Burch WM, Akwari OE: Effect of fatty acids on insulin release: role of chain length and degree of unsaturation. Am J Physiol 1994, 266:E635-E639.

35. Allick G, Bisschop PH, Ackermans MT, Endert E, Meijer AJ, Kuipers F, Sauerwein HP, Romijn JA: A low-carbohydrate/high-fat diet improves glucoregulation in type 2 diabetes mellitus by reducing postabsorptive glycogenolysis. J Clin Endocrinol Metab 2004, 89:6193-6197.

36. Pan DA, Lillioja S, Kriketos AD, Milner MR, Baur LA, Bogardus C, Jenkins AB, Storlien LH: Skeletal muscle triglyceride levels are inversely related to insulin action. Diabetes 1997, 46:983-988.

37. Ciubotaru I, Lee YS, Wander RC: Dietary fish oil decreases C-reactive protein, interleukin-6, and triacylglycerol to $\mathrm{HDL}$-cholesterol ratio in postmenopausal women on HRT. J Nutr Biochem 2003, 14:513-521.

38. Phinney SD: Fatty acids, inflammation, and the metabolic syndrome. Am J Clin Nutr 2005, 82:1178-1184.

39. Turk JR, Carroll JA, Laughlin MH, Thomas TR, Casati J, Bowles DK, Sturek M: C-reactive protein correlates with macrophage accumulation in coronary arteries of hypercholesterolemic pigs. J Appl Physiol 2003, 95:1301-1304.

40. Verhamme P, Quarck R, Hao H, Knaapen M, Dymarkowski S, Bernar H, Van Cleemput J, Janssens S, Vermylen J, Gabbiani G, Kockx M, Holvoet P: Dietary cholesterol withdrawal reduces vascular inflammation and induces coronary plaque stabilization in miniature pigs. Cardiovasc Res 2002, 56:135-144.

41. Pepys MB, Hirschfield GM, Tennent GA, Gallimore R, Kahan MC, Bellotti V, Hawkins PN, Myers RM, Smith MD, Polara A, Cobb AJA, Ley SV, Aquilina A Robinson CV, Sharif I, Gray GA, Sabin CA, Jenvey MC, Kolstoe SE, Thompson D, Wood SP: Targeting C-reactive protein for the treatment of cardiovascular disease. Nature 2006, 440:1217-1221.

42. Bisoendial RJ, Kastelein JJP, Stroes ESG: C-reactive protein and atherogenesis: From fatty streak to clinical event. Atherosclerosis 2007, 195:e10-e18.

43. Koenig W, Khuseyinova N: Biomarkers of atherosclerotic plaque instability and rupture. Arterioscler Thromb Vasc Biol 2007, 27:15-26.

44. Li SH, Szmitko PE, Weisel RD, Wang CH, Fedak PWM, Li RK, Mickle DAG, Verma S: C-reactive protein upregulates complement-inhibitory factors in endothelial cells. Circulation 2004, 109:833-6.

45. Duplus E, Glorian M, Forest C: Fatty acid regulation of gene transcription. J Biol Chem 2000, 275:30749-30752.

46. Ferre $\mathrm{P}$ : The biology of peroxisome proliferator-activated receptors: relationship with lipid metabolism and insulin sensitivity. Diabetes 2004 53:543-50

47. Ishibashi M, Egashira K, Hiasa K, Inoue S, Ni W, Zhao Q, Usui M, Kitamoto S, Ichiki T, Takeshita A: Antiinflammatory and antiarteriosclerotic effects of pioglitazone. Hypertension 2002, 40:687-693.

doi:10.1186/1475-2840-10-64

Cite this article as: Koopmans et al:: Dietary saturated fat/cholesterol, but not unsaturated fat or starch, induces C-reactive protein associated early atherosclerosis and ectopic fat deposition in diabetic pigs. Cardiovascular Diabetology 2011 10:64 